\title{
Tobacco harm reduction in the 21st century
}

\author{
Renée O'Leary and Riccardo Polosa
}

\begin{abstract}
Purpose - This paper aims to overview the need for tobacco harm reduction, the consumer products that facilitate tobacco harm reduction and the barriers to its implementation. The worldwide endemic of tobacco smoking results in the death of over seven million smokers a year. Cigarette quit rates are very low, from 3\%-12\%, and relapse rates are high, from $75 \%-80 \%$ in the first six months and 30\%$40 \%$ even after one year of abstinence. In addition, some smokers do not desire to quit. Cigarette substitution in tobacco harm reduction is one strategy that may reduce the burden of morbidity and mortality.
\end{abstract}

Design/methodology/approach - This review examines the displacement of smoking through substitution of non-combustible low-risk products such as snus, heated tobacco products and e-cigarettes.

Findings - Toxicological testing, population studies, clinical trials and randomized controlled trials demonstrate the potential reductions in exposures for smokers. Many barriers impede the implementation of product substitution in tobacco harm reduction. These products have been subjected to regulatory bans and heavy taxation and are rejected by smokers and society based on misperceptions about nicotine, sensational media headlines and unsubstantiated fears of youth addiction. These barriers will need to be addressed if tobacco harm reduction is to make the maximum impact on the tobacco endemic.

Originality/value - This review provides the rationale for tobacco harm reduction, evaluates the current products available and identifies the barriers to implementation.

Keywords Harm reduction, Snus, e-cigarettes, Tobacco products, Substitution, Nicotine, Tobacco cessation

Paper type Research paper

\section{Introduction}

Tobacco smoking is endemic with more than seven million deaths occurring every year amongst the 1.1 billion smokers worldwide, with $80 \%$ of tobacco users in the world's lowand middle-income countries [World Health Organization (WHO), 2019, tobacco facts]. One of the six primary tactics adopted by the World Health Organization to counter the tobacco epidemic is promoting cessation, the subject of their 2019 annual report.

Achieving high levels of cessation in the tobacco smoking population is an unrealistic goal because successful quit rates are abysmally low, relapse rates are high and in addition, a number of people wish to smoke. Success rates for quitting are approximately 10\% (Fagerström and Eissenberg, 2012), with men and women as equally (un)successful in the US, Canada and Britain (Jarvis et al., 2013). Successful six-month quit rates in the US are 7.6\% [US Department of Health and Human Services (US HHS), 2020]. One-year abstinence achieved with unsupported cessation is 3\% (Benowitz, 2010). Quit rates with support are improved but remain low. Amongst highly motivated patients (238 female, 160 male), smokers with COPD, nicotine replacement therapy (NRT) and counseling resulted in only $12.2 \%$ achieving sevendays of abstinence at 12 months (Ellerbeck et al., 2018).
(Information about the authors can be found at the end of this article.)

Received 5 February 2020 Revised 30 March 2020 14 April 2020

Accepted 20 April 2020

C Renée O'Leary and Riccardo Polosa. Published by Emerald Publishing Limited. This article is published under the Creative Commons Attribution (CC BY 4.0) licence. Anyone may reproduce, distribute, translate and create derivative works of this article (for both commercial and noncommercial purposes), subject to full attribution to the original publication and authors. The full terms of this licence may be seen at: http://creativecommons.org/ licences/by/4.0/legalcode

Expression of concern: The publisher of the journal Drugs and Alcohol Today is issuing an Expression of Concern for the following article O'Leary, R. and Polosa, R. (2020), "Tobacco harm reduction in the $21 \mathrm{st}$ century", published in Drugs and Alcohol Today, Vol. 20 No. 3, pp. 219-234, to inform readers that credible concerns have been raised regarding the editorial process for this article. An investigation is ongoing and is currently unresolved. Further information will be provided by Drugs and Alcohol Today as it becomes available. 
Unfortunately, long-term smokers make fewer attempts to quit as they get older (Babb et al., 2017; Borland et al., 2012; US HHS, 2020).

The compulsion to smoke is very difficult to break. Even for those who do quit smoking, relapse is the norm (Caponnetto et al., 2013; Hughes et al., 2004). For unsupported quit attempts, $80 \%$ relapse in the first month (Benowitz, 2010) and for smokers who use treatment, $75 \%$ fail within six months, with the large majority resuming smoking within two weeks (US HHS, 2010). For Canadian women who abstain from smoking during pregnancy, almost one in four relapses during pregnancy, over one-half relapse after delivery and $70 \%$ to $90 \%$ have relapsed by one-year post-partum (Greaves et al., 2011). Even for those who quit smoking during hospitalization (US) and intended to stay quit (526 female, 416 male), $25 \%$ relapsed on the first day after discharge (no significant difference between genders) (Mussulman et al., 2019).

A Cochrane review (Livingstone-Banks et al., 2019) on relapse prevention interventions for assisted cessation concludes that behavioural interventions provide "no worthwhile benefit in preventing relapse" (p. 2), including interventions specially designed for pregnant and postpartum women. (Substantially extending varenicline use beyond the standard 12 week treatment period was the only effective intervention [RR 1.23, Cl 1.08, 1.41; two studies]; the medication carries risks for negative side effects [US Food and Drug Administration, 2016]). Even a successful one-year quit does not assure that abstinence has been achieved as $30 \%$ to $40 \%$ of former tobacco smokers will eventually relapse (USHHS, 2010) and even as long as after 30 years abstinence, 10\% will relapse to smoking (García-Rodríguez et al., 2013). Consequently, there is a pressing need for alternative and more efficient means to reduce or prevent harm in those who return to smoking.

Why do former smokers relapse, even after years of cessation and other smokers chose not to quit? First of all, nicotine use is pleasurable (Benowitz, 2010). Nicotine use has benefits as follows:

In human studies, acute administration of nicotine can have positive effects on cognitive processes, such as improving attention, fine motor coordination, concentration, memory, speed of information processing, and alleviation of boredom or drowsiness. Some nicotine users benefit from self-medication effects for alleviation of stress, anxiety, depression, and other mental health and medical conditions, including schizophrenia and Parkingson's disease. (Niaura, 2016, p. 3).

Considering the positive effects of nicotine, could society become tolerant of recreational nicotine use with e-cigarettes "to speed the obsolescence of cigarettes" (Abrams et al., 2015, p. 154)? This question extends the scope of tobacco harm reduction into larger questions of social acceptance and the legal regulation of drug use.

Harm reduction is a public health strategy to reduce the harms caused by particular behaviours, one of which is drug use. The tactics include amending regulations and bans that increase harm, empowering people with accurate information and offering alternatives such as the adoption of risk reduced modes of use (for example, clean needles) and the substitution of lower-risk drugs (for example, methadone maintenance). Tobacco harm reduction seeks to prevent or reduce the damage caused by the toxins generated by tobacco combustion for smokers unable or unwilling to stop, rather than aiming at complete abstinence from nicotine use (Zeller and Hatsukami, 2009). The World Health Organization's Framework Convention on Tobacco Control (FCTC) (WHO, 2003) acknowledges harm reduction as an integral part of a comprehensive approach, but it does so only in reference to eliminating or reducing consumption. In regard to tobacco use itself, the FCTC programme is abstinence based (Meier and Shelley, 2006).

This commentary focuses on the substitution of lower-risk products for smoking. Displacing combustible tobacco products with non-combustion products that deliver nicotine with a lower toxic and risk profile is key to tobacco harm reduction, and may promote the 
cessation of cigarette smoking. In the 21st century, three classes of products can fulfill this role, namely, snus (oral use tobacco), e-cigarettes (vapor products) and heated tobacco products (heat-not-burn). Examples of the evidence for the harm reduction potential offered by these products is presented, based on the reductions of toxicity in these products compared to smoking cigarettes. This evidence is followed by a discussion of the barriers to tobacco harm reduction. This article is not a systematic or narrative review; it is an overview of recent studies applicable to the substitution of reduced-risk products and emerging literature, which addresses barriers to tobacco harm reduction. Industry conducted or funded studies were excluded.

For those seeking a comprehensive source of studies on e-cigarettes, a systematic review providing the evidence on tobacco harm reduction is available in the US National Academies of Sciences, Engineering and Medicine (2018) book, Public Health Consequences of E-Cigarettes. This exhaustive review states.

There is conclusive evidence that completely substituting e-cigarettes for combustible tobacco cigarettes reduces users' exposure to numerous toxicants and carcinogens present in combustible tobacco cigarettes. There is substantial evidence that completely switching from regular use of combustible tobacco cigarettes to e-cigarettes results in reduced short-term adverse health outcomes in several organ systems" (p. 11, emphasis in original)

A comprehensive narrative review is Evidence Review of E-Cigarettes and Heated Tobacco Products, 2018. A Report Commissioned by Public Health England and an update Vaping in England: An Evidence Update Including Mental Health and Pregnancy, March 2020: A Report Commissioned by Public Health England.

\section{Snus and smokeless (oral) tobacco}

Snus is an oral tobacco product with processed tobacco in a paper pouch that the user places in the mouth between the gum and cheek. It is not the same product as chewing or dip tobacco. Snus tobacco is pasteurized, which greatly reduces the level of nitrosamines, tobacco compounds responsible for tobacco-related diseases (O'Connor et al., 2009). Another harm reduction benefit of snus is that its use does not generate second-hand smoke exposures.

The harm reduction potential of snus can be observed at the population level. A comparative case study by Ramstrom and Wikmans (2014) analysed the WHO Global Report on Mortality Attributable to Tobacco (2004 data) to compare rates for smokingrelated mortality between male snus users in Sweden to men in European countries overall where snus is banned. Both populations had a similar prevalence of daily tobacco use. Swedish men had lower rates of lung cancer deaths for men 60-69 years of age, at 87 per 100,000 compared to the European Union average of 220 and lower rates of cardiovascular death at 72 compared to 170 per 100,000, respectively.

Although the prevalence of women regular snus users is far lower than for men in Sweden (4\% compared to $19 \%$ in 2015), snus uptake by smokers of either gender resulted in high smoking quit rates of $71.6 \%$ for women and $76.3 \%$ for men (Ramström et al., 2016). Regular snus use by youth appears to be protective against smoking uptake, even more so amongst female youth, with only $8.2 \%$ of girls and $17.6 \%$ of boys who regularly used snus progressing to daily smoking (Ramström et al., 2016).

At the individual level, a randomized controlled trial by Meier et al. (2019) enrolled 150 adult smokers (85 male, 65 female) in an eight-week multi-site study comparing usual cigarette use, partial substitution of snus for cigarette use and complete substitution of snus. They conclude that complete substitution reduced exposure to the harmful constituents of acrolein, crotonaldehyde, acrylonitrile and acrylamide, but not others (nitrosamine ketone 
[NNK], propylene oxide, phenanthrene). Additionally, snus-only users had significantly lower levels of carbon monoxide (eCO) than the smoking arm, a cardiovascular risk factor.

The harm reduction value of snus has recently been validated by the USFDA as it granted Swedish Match USA on 22 October 2019 a "modified risk order" for eight snus general brand products. Swedish Match snus is the first set of products approved as a modified risk tobacco product (MRTP), a product category for proven reduced-risk products as determined by the USFDA. The USFDA announced that "the available scientific evidence, including long-term epidemiological studies, shows that relative to cigarette smoking, exclusive use of these specific smokeless tobacco products poses a lower risk of mouth cancer, heart disease, lung cancer, stroke, emphysema and chronic bronchitis" (USFDA, 22 October 2019). In addition, the USFDA observed that the levels of N-Nitrosonornicotine (NNN) and nitrosamine ketone (NNK), two major carcinogens, are much lower in the Swedish snus products than in smokeless products sold in the USA.

The process for acquiring the MRTP designation from the US FDA is lengthy and stringent and it can be terminated at any point. It begins with a premeeting with the tobacco products scientific advisory committee, followed by a filing review, a substantive review with a comment period and final action. Following approval, the FDA requires post-market reporting and renewal. The filing, which must be submitted for each individual product, is required to contain all company testing reports; studies on population and individual health effects; proposed product packaging, labeling and advertising; and product testing demonstrating how customers actually use the product and their understanding of its risks (US Food and Drug Administration, 2020).

Other smokeless tobacco products show evidence of harm reduction. An extensive study of over 46,000 US men 40-79 years of age from 1987 to 2010 (US National Health Interview Survey) found no increases in mortality amongst smokeless-tobacco-users compared to never-tobacco-users for cardiovascular diseases, all cancers and malignancies (Rodu and Plurphanswat, 2019). Different types of oral tobacco products (that vary by country) carry substantially different levels of risk for oral cancers (Asthana et al., 2018), therefore they vary in their efficiency for tobacco harm reduction. An amazing finding of a five-year study of 879 Yup'ik people of Alaska (406 male, 468 female) is that users of Iq'mik, a smokeless tobacco produced with tree ash, have a lower risk for negative cardiometabolic health than non-smokers as indicated by multiple biomarker tests (Ryman et al., 2018).

\section{Heated tobacco products}

Heated tobacco products, also known as heat-not-burn, apply heat from an electronically controlled holder to tobacco sticks, plugs or capsules. Heat-not-burn products are "IQOS" by Philip Morris International, "glo" by British American Tobacco and "Ploom TECH" by Japan Tobacco International. The user places the tobacco product in a holder and draws on it in the same fashion as cigarettes or cigars. Philip Morris initiated the MRTP process for three IQOS products in January 2018 and the comment period closed on 24, February 2020, so a decision is many months away (USFDA, 2020). A group of researchers has published concerns that the submission does not include data on all of the product's harmful and potentially harmful constituents (St. Helen et al., 2018).

Limited evidence indicates that heated tobacco products offer the potential for tobacco harm reduction, but not as much reduction in toxicants as e-cigarettes (Public Health England, 2018). In four non-industry studies, heated tobacco products demonstrated reductions in exposures compared to cigarettes. In a human subject clinical trial, 12 adult smokers (6 male, 6 female) experienced no elevation in eCO levels (a risk factor for cardiovascular disease) after brief use of a heated tobacco product (Caponnetto et al., 2018) and another trial (20 male, 10 female) found a small but minimal increase (Adrianes, Van Gucht and Baeynes, 2018). A toxicological product assessment conducted with the 
Canadian machine smoking procedure found levels of aldehydes at approximately $80 \%-$ 95\% lower than cigarettes and volatile organic compounds approximately 97\%-99\% lower (Mallock et al., 2018). Another toxicological study using a margin of exposure analysis reported that a heated tobacco product reduced the risks from exposure to 9 out of the 20 most toxic compounds in tobacco (Lachenmeier et al., 2018).

Heated tobacco products are becoming very popular in a number of countries, including Japan and South Korea. Japan has $90 \%$ of the global market for heated tobacco products (Filter Magazine, 2019), although the prevalence of past-month users in 2018 is only $2.7 \%$ of the population, and the users are predominantly men (76.0\% male vs $24.0 \%$ female) (Sutanto et al., 2019). A particular appeal of heated tobacco products for Japanese smokers is eliminating the social disapproval of the smell of second-hand smoke (Hair et al., 2018; Tabuchi et al., 2018). In South Korea, sales of these products increased from 79 million packs in 2017 to 332 million packs in 2018 (Filter Magazine, 2019) and expected to increase 21\% annually (Korea Times, 2019). In other major markets for heated tobacco products, sales increased rapidly from 2017 to 2018 as follows: 300\% in Italy and over $500 \%$ in Russia (Passport, 2020).

\section{E-cigarettes}

Electronic cigarettes are products that operate by heating an element that vaporizes a solution (e-liquid) mainly consisting of glycerol, propylene glycol, distilled water, and flavourings and which may or may not contain nicotine. Heating generates an aerosol (vapour) that is inhaled (vaping). Their design and efficiency in nicotine delivery have improved substantially since their market introduction in 2006. There are three e-cigarette designs as follows:

1. a disposable product;

2. a reusable, refillable device filled with liquid by the users (tank system); and

3. a reusable device, which attaches to pre-filled cartridges ("carts" or "pods") such as JUUL.

Many current e-cigarette devices are designed so that the user can regulate its power, effecting the heating temperature.

Worldwide, e-cigarettes have grown dramatically in popularity, increasing from about seven million users in 2011 to 41 million in 2018. (Euromonitor International, quoted in Jones, 2019). E-cigarettes are regulated in the European Union by the Tobacco Products Directive 2014/40/EU and in the US under the Deeming Rule published 5 May 2016. Outside of the US and the European Union, no other countries, which permit the sale of e-cigarettes have enacted product safety requirements beyond regulating nicotine content (Institute for Global Tobacco Control, 2020).

New studies provide evidence for the harm reduction potential of e-cigarettes. A randomized controlled trial (Hajek et al., 2019) of 886 motivated quitters (460 male, 424 female) at the UK National Heath Stop Smoking Service compared e-cigarettes and NRTs for successful cessation at one year (no more than five cigarettes after the 2nd week) with biochemical verification and drop-outs calculated as treatment failures (intention-to-treat analysis). The quit rates were $18.0 \%$ for e-cigarettes compared to $9.9 \%$ with NRT (RR 1.83; $\mathrm{Cl} 1.30,2.58 ; p<0.001 ; 85 \%$ power). For those achieving one-year abstinence with ecigarettes, $80 \%$ were still using e-cigarettes at the one-year follow-up (63 of 79 participants), a possible indication of the effectiveness of e-cigarettes for preventing relapse.

Another human subject study is a cross-sectional trial (Shahab et al., 2017) of $N=181$ (110 male, 71 female) participants (London) biochemically tested for biomarkers of exposure in 
five groups of 36-37 participants as follows: cigarette-only-users, e-cigarettes-only-users (>6 months smoking cessation), NRT-only-users ( $>6$ months smoking cessation), dualusers of cigarettes and e-cigarettes and dual-users of cigarettes and NRT. The e-cigarette-only users had significantly lower NNAL levels than all other groups-equivalent to a $97 \%$ reduction compared to combustible cigarette-only users. A finding of particular importance is the lowered biomarker of 1,3-butadiene for e-cigarette-only-users at $11.0 \%$ $(\mathrm{Cl} 7.5,16.1)$ that of smokers; $\mathrm{BDE}$ is the greatest source of cancer risk in cigarettes (Fowles and Dybing, 2003). E-cigarette-only-users recorded acrylonitrile levels at 2.9\% (Cl $1.7,4.7$ ) that of smokers, the second-highest source of cancer risk (ibid.). While biomarkers are not indicators of disease rates, the substantial reductions in exposures for e-cigaretteonly-users is a positive marker for tobacco harm reduction. Another important reduction of exposure provided by e-cigarette use compared to smoking is the elimination of elevated levels of exhaled carbon monoxide, a major risk factor for cardiovascular disease, demonstrated in a clinical trial of 30 participants (20 male, 10 female) (Adrianes, Van Gucht and Baeynes, 2018).

As discussed earlier, relapse is a common problem for smoking cessation. A new study drawn from survey data indicates the effectiveness of e-cigarette use to prevent relapse. Based on combined data from the 2014 and 2015 US National Health Interview Surveys (53.6\% male), the prevalence of being quit during the prior six years was significantly higher amongst daily e-cigarette users compared to those who had never used e-cigarettes (52.2\% vs $28.2 \%$, APR: 3.15 [2.66, 3.73]). After adjustment for covariates, daily e-cigarette use was consistently the strongest independent correlate of smoking cessation and did not vary by gender (Giovenco and Delnevo, 2018).

So how could e-cigarette use the act to prevent relapse? A qualitative study of 40 UK vapers (20 male, 20 female) suggests that "for some, e-cigarettes can substitute the physical, psychological, social, cultural and identity-related dimensions that were previously enjoyed about tobacco smoking, and thus, may uniquely support long-term smoking relapse prevention" (Notley et al., 2018, p. 10). These same factors could also function to support e-cigarette substitution for smoking.

\section{Patterns of use for tobacco harm reduction}

Still, another factor must be considered for harm reduction to be realized the dual-use of ecigarettes and cigarettes. Researchers cited in this article state that the concurrent use of cigarettes with other reduced-harm products does not confer demonstrable benefits.

- Meier et al. (2019) "potential harm reduction can only be realized if smokers are instructed to stop smoking and completely switch to snus" (p. 6).

- Mallock et al. (2019) "a complete switch to HTP (heated tobacco products) can reduce toxicant exposure [...] dual use could counteract potential benefits" (p. 3).

- Shahab et al. (2017) "dual use of e-cigarettes with combustible cigarettes did not reduce exposure appreciably. Therefore, e-cigarettes are likely to be beneficial only if the complete cessation of combustible cigarette smoking is achieved" (p. 397).

Dual-use may negate the potential harm reduction benefits of combustion-free nicotine delivery technologies because of the extensive toxicity of tobacco cigarettes. Consumption of as few as one to five cigarettes a day may result in significant risks for disease (Bjartveit and Tverdal, 2005; Hatsukami and Parascandola, 2005; Schane et al., 2010). For tobacco harm reduction, partial substitution is generally ineffective - substitution must be complete and sustained for effectiveness.

Our understanding of dual-use is limited due to the paucity of studies. The longitudinal PATH study from 2013 to 2015 assessed 1,082 US adults classified as dual users and after 
one year $25.5 \%$ remained dual users, $59.2 \%$ returned to only cigarette use, $4.8 \%$ transitioned to exclusive e-cigarette use and $6.7 \%$ reported complete abstinence (Miller, Smith and Goniewicz, 2020; data also analysed in other studies). While the quit rate was favourable in comparison to the benchmarks referenced earlier, the high percentage of users abandoning e-cigarettes may well have been due to the models available at that time, which had inferior levels of nicotine delivery. For youth dual users, a two year longitudinal study of youth $15-21$ years old ( $N=15,275,51.3 \%$ male, $6.1 \%$ dual users), approximately $20 \%$ of dual users at baseline transitioned to exclusive cigarette use, but the transitions between the products used varied considerably over the timespan of the study (Hair et al., 2019). Studies of dual use have not supplied detailed data on the frequencies of use for each product, a critical shortcoming. A 2018 US study ( $N=5,989$, dual users 3.7\% in 2018) found that many dual users appear to have cut down their cigarette use as $67.6 \%$ of dual users reported smoking cigarettes on less than 10 days in the past month (Owosu et al., 2019), but the number of cigarettes smoked on those days is unknown. The trajectory of dual use and the motivations for this pattern of use remain unclear.

\section{Barriers to tobacco harm reduction}

The barriers to tobacco harm reduction originate in regulation and misperceptions. Smokers' access to low-risk products is thwarted by product bans. The misperception of the risks of these products results in smokers rejecting them, misperceptions that arise from inaccurate information and sensational media headlines. Public health officials are misinformed by these sources as well, plus they buttress their opposition to tobacco harm reduction products with unsubstantiated fears of youth addiction. These barriers will need to be addressed if tobacco harm reduction is to make the maximum impact on the tobacco endemic.

\section{Bans, regulations and taxes}

Tobacco harm reduction products are subject to bans in various countries. Snus is banned in Australia, New Zealand and the European Union except for Sweden. By 2018, six countries had banned heated tobacco products (Johns Hopkins, 2018). Bans are even more widespread for e-cigarettes with 30 countries banning all e-cigarettes and seven countries banning nicotine-containing e-cigarettes (Institute for Global Tobacco Control, 2020, plus author's updating). Not only do bans preclude the adoption of harm reduction strategies but also they can foster a black market for the products. For example, Australia's ban on nicotine e-cigarettes has given rise to a black market for nicotine liquids (Hall and Gartner, 2014).

Regulations restricting the sale of vapour product flavours may also impede tobacco harm reduction. In the UK just under 1 in 5 current vapers surveyed $(N=699)$ stated they would increase or return to smoking if a ban on flavours was enacted. About one in four said they would look for "other sources", suggesting a possible turn to black market sources (ASH Smokefree Great Britain Adult Survey 2019, cited in McNeill et al., 2020).

Increasing taxes on reduced-risk products could function to deter smokers from switching to them. As of the beginning of 2020, 14 counties have placed taxes on e-cigarettes (Institute for Global Tobacco Control, 2020). The (US) National Bureau of Economic Research (Saffer et al., 2019) used a synthetic control design comparing the smoking prevalence trends in Minnesota, where e-cigarettes have been heavily taxed since 2010, to the rest of the US and concluded that approximately 32,400 adult smokers in that state had been deterred from quitting over the 10 year period. The authors state unequivocally that "we find consistent evidence that higher e-cig taxes increase adult smoking rates and reduce quits" (p. 3). Their calculations demonstrate that taxing e-cigarettes at the same rate 
as tobacco would increase the baseline smoking rate in the US by $8.1 \%$ and decrease the quit rate by $25 \%$.

\section{Misperceptions about nicotine}

Studies have long established the fact that for adult smokers, nicotine per se may cause addiction, but not disease, therefore substituting non-combustion modes of nicotine delivery for smoking results in harm reduction. Dr Neil Benowitz, a leading researcher in nicotine pharmacology, states that "nicotine plays a minor role, if any, in causing smokinginduced diseases" (Benowitz, 2010, p. 2295).

Unfortunately, serious misperceptions about nicotine abound, amongst both clinicians and the public. The misperception of nicotine's harms amongst health-care professionals has received almost no attention but appears to be pervasive. A pencil and paper survey (Patel et al., 2013) of 826 full-time faculty members (57\% male respondents) in the schools of medicine, public health, dentistry and nursing at the University of Louisville (US) found that $38 \%$ believed that nicotine, separate from smoking, is a high-risk factor for heart attack and stroke and an additional 50\% deemed nicotine itself as a moderate risk factor. For all cancers, 38\% ranked nicotine a high-risk factor and another $37 \%$ rated the risk as moderate; for oral cancer, the percentages were $32 \%$ and $40 \%$, respectively. Male professors appear to be somewhat better informed than female professors, as male professors were significantly more likely to rate cigarettes as riskier than nicotine, by ORs of 1.88 - 2.30. In an online survey (Ferrara et al., 2019) of 256 European Union residents in public health (143 female, 106 male), 62\% stated that nicotine itself causes cancer and over $72 \%$ considered nicotine responsible for atherosclerosis. These high percentages of medical professionals holding misconceptions about nicotine as a cause of these disease are certainly troubling.

So is it any wonder that the public too holds the misperception that nicotine causes disease? In the UK, 40\% of the public believe that nicotine is the cause of smoking-related cancers (McNeill et al., 2018). This widespread misperception of nicotine as a cause of disease, a belief held equally amongst men and women smokers, may also explain in part the relatively low utilization of NRT (Black et al., 2012). Even amongst smokers who chose NRT for treatment, a study of 1,047 clients at the UK stop-smoking services found only $6.0 \%$ (Cl 4.3, 8.3) were using NRT at the one-year follow-up (Shahab et al., 2016), indicating the limited success of NRT for substitution.

Abrams et al. (2018, p. 205) stress the need to separate the consequences of nicotine addiction from the concerns about harms to adults from smoking, stating that "the mistaken public beliefs that nicotine is the cause of disease risk and cancer, rather than the smoke from combustion, must be dispelled". There is a crying need for better education of medical professionals on the effects of nicotine during their training and through continuing medical education, and through them, the delivery of accurate information to smokers and the public as well.

\section{Misperceptions of relative risks}

For snus, even with its USFDA designation as a MRTP, acceptance by smokers appears to be a long road as indicated by US smokers' risk misperceptions about snus. A survey of $N$ $=256$ US smokers (49.6\% male) found that 44\% perceived snus as equally or more harmful than cigarettes and only $17 \%$ understood that snus carries a lower risk for lung cancer, with those perceptions not differing significantly between men and women (Wackowski et al., 2019).

For e-cigarettes, misperceptions of their relative harm compared with cigarettes has continued to increase. In the UK, $34 \%$ of smokers believe that vaping is less harmful than 
smoking (Smoking Toolkit study 2019, cited in McNeill et al., 2020). In the US tobacco products and risk perceptions survey 2018 (51\% women), 25.8\% believed that e-cigarettes were less harmful than smoking (Nyman et al., 2019). For tobacco harm reduction to be a workable strategy, the public must be persuaded of the evidence for the lower relative risks of e-cigarettes and snus compared to smoking.

\section{Media sensationalism}

Media misrepresentations of e-cigarette studies are causing the public to disbelieve the lower relative risks of products for tobacco harm reduction, a situation so pervasive that the 2018 Public Health England report (McNeill et al.) devotes an entire chapter to the subject. The authors of the report also point at several academic studies with skewed conclusions.

A salient example of media misrepresentation is its coverage of the recent outbreak of acute severe cases of lung injury and deaths in the US in the fall of 2019, e-cigarette or vaping product use associated lung injury (EVALI). For several months commercial vaping products were blamed for the illnesses and deaths in numerous newspapers, TV and radio stories (Gartner, Bonevski and Hall, 2020).

Although the data were available on the US CDC website (US CDC, 21 Nov 2019), the media failed to report that $82 \%$ of cases (66\% male) were amongst users of illegal tetrahydrocannabinol (THC) cartridges, not including underage patients who may not have admitted to their illegal activities. The USFDA shut down 44 illegal THR online vape sites with Operation Vapor Lock (US Food and Drug Administration, 2019) and subsequently, the number of new cases plummeted (Hartnett et al., 2019). With new cases down to near zero and having identified vitamin-E acetate - a thickening agent in illegal/black market THC liquids consumed with vapourizers - as the culprit of the outbreak, the CDC stopped reporting on EVALI on 25 February 2020.

The media gave little attention to these important developments and to the fact that the outbreak was confined to the US black market supply chain, with no cases of the lung illness being reported amongst users in the European Union (European Commission Directorate-General for Health and Food Safety, 2019) or elsewhere in the world except for a few cases in neighboring Canada. Moreover, no appreciable effort was spent by the media in rectifying the misinformation.

Months of sensationalized reporting that erroneously implicated all vapour products appears to have persuaded large numbers of the public and clinicians around the world to erroneously believe that commercial e-cigarettes are extremely dangerous. Surveys have yet to be conducted on the impact of EVALI on the perception of e-cigarettes; McNeill et al. (2020) suspect that EVALI reporting influenced the sharp increase in 2019 in the number of UK smokers who believe that vaping is more harmful than smoking. The fallout of this event on tobacco harm reduction remains to be seen.

\section{Fears of youth nicotine addiction}

Probably the most powerful barrier to tobacco harm reduction is the fear that e-cigarette use by youth use will lead to nicotine addiction and thereby increase the uptake of tobacco products. Surveys apply the metric of "any e-cigarette use in the past 30 days" as an indicator of adolescent habituation. Yet, in the real world, $26 \%$ of US 12th grade students classified with this metric reported vaping only once or twice a month (from Table 4-4a, Meich et al., 2019) and amongst the $20.1 \%$ of US high school students reporting any past-30-day use (in the 2018 National Youth Tobacco Survey), just under half had vaped on one to five days (Glasser et al., 2020). In the UK approximately 2 out of 3 past-30-day users (15 years old) were vaping less than once a week (Smoking Drinking and Drug Survey, 2019, cited in McNeill et al., 2020). Moreover, while the prevalence of youth vaping has increased in the US and Canada, it has been relatively 
unchanged elsewhere such as in the UK (McNeill et al., 2020) and Finland (Finnish Government Ministry of Social Affairs and Health, 2019).

Nor are all youth users vaping nicotine. In 2018, the US Monitoring the Future survey the prevalence of nicotine use was $5.7 \%$ for those vaping once or twice a month amongst 12 th grade students (past-30-day users) and 2.8\% for those vaping 3-5 times a month, with female students significantly less likely to vape nicotine (Meich et al., 2019). In Ontario Canada, in 2019 (after nicotine e-cigarettes were legalized), 17.8\% of 7-12 grade students who were any-past-year users vaped only non-nicotine products and another $20.7 \%$ reported using both nicotine and non-nicotine products (Boak et al., 2020). A survey of Los Angeles CA youth 16 to 18 years old with any-past-30-day use of nicotine vaping found that $17.6 \%(n=233)$ self-reported one or more symptoms of nicotine dependence and $12.0 \%$ reported two or more (Vogel et al., 2020), but the authors do not report the specific frequency of use for those reporting symptoms.

The DSM-5 diagnostic criteria for tobacco use disorder requires impairment or distress with two of 11 symptoms and is "uncommon amongst individuals who do not use tobacco daily" (American Psychiatric Association, 2013). Furthermore, the ICD-10 code F17.2 for tobacco use distinguishes between harmful use and dependence. A reasonable estimation of the prevalence or potential for problematic use amongst youth who vape is substantially overreported by the metric of any-past-30-day use.

\section{Closing remarks and future research}

In conclusion, to reduce smoking and to save millions of lives, tobacco harm reduction in the form of cigarette substitution with low-risk products appears to be a promising path. These products, although not completely risk-free, offer an alternative to quit or die. In consideration of the available evidence, advice to tobacco smokers should include trying substitute products. The obvious fact so often overlooked is that smoking is rewarding and people like to do it. Giving smokers an alternative with efficient nicotine delivery means that they might prefer one of these products over cigarettes. Tobacco harm reduction will produce better outcomes if the alternatives incur substantially less risk than smoking tobacco cigarettes. There are numerous barriers to overcome to make these products accessible and acceptable to smokers. For those of us committed to tobacco harm reduction, there is no turning back - we will advocate for our patients, families, friends and fellow world citizens for their right to avail themselves of snus, heated tobacco products and e-cigarettes.

The field of tobacco harm reduction is in sore need of more research if this public health strategy is to make a meaningful impact on the tobacco epidemic.

Studies and reviews on cessation should specify quit rates, statistics absent from the current Cochrane review on cessation, 2018 WHO M-Power Report and many other studies. Public health researchers must be forthright about the effectiveness of cessation treatments so that the necessity of tobacco harm reduction can be put in a proper perspective.

The impacts of taxation and flavour bans require continued surveillance for their potential negative effects on product uptake. Cross country case comparisons between countries with and without bans on vapour products, snus and heated tobacco products could shed light on their population-level effects on cessation, morbidity and mortality rates.

In place of the common measurement of any-past-30-day use, accurate metrics must be developed to determine what frequencies of use of reduced-risk products may result in youth nicotine dependence. To understand youth vaping, the gateway and common liabilities arguments must be presented in studies as what they are: hypotheses.

As noted earlier, studies on dual-use need to collect detailed data on the frequency of use of each product and longitudinal research is necessary to understand how these patterns of 
use impact tobacco consumption and cessation. In addition, qualitative studies should be undertaken to understand the motivations for dual-use.

Qualitative research is also needed to identify the reasons for the use of reduced-risk products missed by the standard closed-ended questions on surveys used in tobacco control. Current studies are likely missing reasons for use such as in Japan where concerns about social etiquette around second-hand smoke appear to be driving sales of heated tobacco products.

Finally, more methodologically sound clinical studies on the health impacts of snus, heated tobacco products and e-cigarettes are certainly necessary. Differences in the risk profiles of non-combustion nicotine products need to be quantified and regulatory policies and clinical recommendations should be sufficiently nuanced to address their different risk profiles. Studies observing the health of long-term users of these products are a must. At the population level, prevalence rates of smoking-related diseases in relation to tobacco sales, harm reduction product uptake and changes in the prevalence of cigarette use would indicate the potential benefits or shortcomings of tobacco harm reduction strategies.

\section{References}

Abrams, D.B., Glasser, A., Villanti, A.C. and Niaura, R. (2015), "Cigarettes: the rise and decline but not the demise of the greatest behavioral health disaster of the 20th century", in Kaplan, R., Spittel, M. and David, D. (Eds), Emerging Behavioral and Social Science Perspectives on Population Health, AHRQ Publication, pp. 143-168.

Abrams, D.B., Glasser, A.M., Pearson, J.L., Villanti, A.C., Collins, L.K. and Niaura, R.S. (2018), "Harm minimization and tobacco control: reframing societal views of nicotine use to rapidly save lives", Annual Review of Public Health, Vol. 39 No. 1, pp. 193-213.

American Psychiatric Association (2013), Diagnostic and Statistical Manual of Mental Disorders, 5th ed., American Psychiatric Association, Washington, DC

Asthana, S., Labani, S., Kailash, U., Sinha, D.N. and Mehrotra, R. (2018), "Association of smokeless tobacco use and oral cancer: a systematic global review and meta-analysis", Nicotine and Tobacco Research, Vol 21 No. 9, pp. 1162-1171.

Babb, S., Malarcher, A., Schauer, G., Asman, K. and Jamal, A. (2017), "Quitting smoking among adults - the United States, 2000-2015", Morbidity and Mortality Weekly Report, Vol. 65 No. 52, pp. 1457-1464.

Benowitz, N.L. (2010), "Nicotine addiction", New England Journal of Medicine, Vol. 362 No. 24, pp. 2295-2303.

Bjartveit, K. and Tverdal, A. (2005), "Health consequences of smoking 1-4 cigarettes per day", Tobacco Control, Vol. 14 No. 5, pp. 315-320.

Black, A., Beard, E., Brown, J., Fidler, J. and West, R. (2012), "Beliefs about the harms of long-term use of nicotine replacement therapy: perceptions of smokers in England", Addiction, Vol. 107 No. 11, pp. 2037-2042.

Boak, A., Elton-Marshall, T., Mann, R.E. and Hamilton, H.A. (2020), Drug Use among Ontario Students, 1977-2019: Detailed Findings from the Ontario Student Drug Use and Health Survey (OSDUHS), Centre for Addiction and Mental Health, Toronto, ON.

Borland, R., Partos, T.R., Yong, H.-H., Cummings, K.M. and Hyland, A. (2012), "How much unsuccessful quitting activity is going on among adult smokers? Data from the international tobacco control fourcountry cohort survey", Addiction, Vol. 107 No. 3, pp. 673-682.

Caponnetto, P., Keller, E., Bruno, C.M. and Polosa, R. (2013), "Handling relapse in smoking cessation: strategies and recommendations", Internal and Emergency Medicine, Vol. 8 No. 1, pp. 7-12.

Caponnetto, P., Maglia, M., Prosperini, G., Busà, B. and Polosa, R. (2018), "Carbon monoxide levels after inhalation from new generation heated tobacco products", Respiratory Research, Vol. 19 No. 1, pp. 1-4. 
Ellerbeck, E.F., Nollen, N., Hutcheson, T.D., Phadnis, M., Fitzgerald, S.A., Vacek, J., Sharpe, M.R., Salzman, G.A. and Richter, K.P. (2018), "Effect of long-term nicotine replacement therapy vs standard smoking cessation for smokers with chronic lung disease: a randomized clinical trial", JAMA Network Open, Vol. 1 No. 5, pp. 1-14.

European Commission Directorate-General for Health and Food Safety (2019), "Meeting on the group of experts on tobacco policy, October 15", available at: https:/lec.europa.eu/health/sites/health/files/ tobacco/docs/ev_20171016_sr_en.pdf (accessed 15 January 2020).

Fagerström, K. and Eissenberg, T. (2012), "Dependence on tobacco and nicotine products: a case for product-specific assessment", Nicotine \& Tobacco Research, Vol. 14 No. 11, pp. 1382-1390.

Ferrara, P., Shantikumar, S., Cabral Veríssimo, V., Ruiz-Montero, R., Masuet-Aumatell, C. and RamonTorrell, J.M. (2019), "Knowledge about e-cigarettes and tobacco harm reduction among public health residents in Europe", International Journal of Environmental Research and Public Health, Vol. 16 No. 12, pp. 1-13.

Filter Magazine (2019), "Rise of heat-not-burn products coincides with a decrease in cigarette sales", January 29, available at: https://filtermag.org/rise-of-heat-not-burn-products-correlates-with-decreasein-cigarette-sales/ (accessed 15 January 2020).

Finnish Government Ministry of Social Affairs and Health (2019), "Adolescent health and lifestyle survey: smoking and drinking among young people no longer decreasing [press release]", August 16, available at: https://valtioneuvosto.fi/en/article//asset_publisher/1271139/terveystapatutkimus-nuorten-tupakan-jaalkoholin-kaytto-ei-enaa-vahene (accessed 19 March 2020).

Fowles, J. and Dybing, E. (2003), "Application of toxicological risk assessment principles to the chemical constituents of cigarette smoke”, Tobacco Control, Vol. 12 No. 4, pp. 424-430.

García-Rodríguez, O., Secades-Villa, R., Flórez-Salamanca, L., Okuda, M., Liu, S.M. and Blanco, C. (2013), "Probability and predictors of relapse to smoking: results of the national epidemiologic survey on alcohol and related conditions (NESARC)", Drug and Alcohol Dependence, Vol. 132 No. 3, pp. 479-485.

Gartner, C., Bonevski, B. and Hall, W. (2020), "Miscommunication about the causes of the US outbreak of lung diseases in vapers by public health authorities and the media", Drug and Alcohol Review, Vol. 39 No. 1, pp. 3-6.

Giovenco, D.P. and Delnevo, C.D. (2018), "Prevalence of population smoking cessation by electronic cigarette use status in a national sample of recent smokers", Addictive Behaviors, Vol. 76, pp. 129-134.

Glasser, A.M., Johnson, A.L., Niaura, R.S., Abrams, D.B. and Pearson, J.L. (2020), "Youth vaping and tobacco use in a context in the United States: results from the 2018 national youth tobacco survey", Nicotine \& Tobacco Research, pp. 1-7.

Greaves, L., Poole, N., Okoli, C.T.C., Hemsing, N., Qu, A., Bialystok, L. and O'Leary, R. (2011), Expecting to Quit: A Best-Practices Review of Smoking Cessation Interventions for Pregnant and Postpartum Girls and Women, British Columbia Centre of Excellence for Women's' Health, Vancouver.

Hair, E.C., Bennett, M., Sheen, E., Cantrell, J., Briggs, J., Fenn, Z., Willett, J.G. and Vallone, D. (2018), "Examining perceptions about IQOS heated tobacco product: consumer studies in Japan and Switzerland", Tobacco Control, Vol. 27, pp. s70-s73.

Hajek, P., Phillips-Waller, A., Przulj, D., Pesola, F., Myers Smith, K., Bisal, N., Li, J., Parrorr, S., Sasieni, P., Dawkins, L., Ross, L., Goniewicz, M., Wu, Q. and McRobbie, H.J. (2019), "A randomized trial of e-cigarettes versus nicotine-replacement therapy", New England Journal of Medicine, Vol. 380 No. 7, pp. 629-637.

Hall, W. and Gartner, C. (2014), "Should Australia reconsider its ban on the sale of electronic nicotine delivery systems?", The Lancet Respiratory Medicine, Vol. 2 No. 8, pp. 602-604.

Hartnett, K.P., Kite-Powell, A., Patel, M.T., Haag, B.L., Sheppard, M.J., Dias, T.P., King, B.A., Melstrom, P.C., Ritchey, M.D., Stein, Z. and Idaikkadar, N. (2019), "Syndromic surveillance for ecigarette, or vaping, product use-associated lung injury", New England Journal of Medicine, Vol. 382 No. 8, pp. 766-772.

Hatsukami, D.K., (2005). and Parascandola, M. "Tobacco harm reduction", in Boyle, P., Gray, N., Henningfield, J., Seffrin, J. and Zatonski, W.A. (Eds), Tobacco: Science, Policy, and Public Health, 2nd ed., Oxford University Press, Oxford, pp. 675-690. 
Hughes, J.R., Keely, J. and Naud, S. (2004), "Shape of the relapse curve and long-term abstinence among untreated smokers", Addiction, Vol. 99 No. 1, pp. 29-38.

Institute for Global Tobacco Control (2020), Country Laws Regulating E-cigarettes: A Policy Scan, Johns Hopkins Bloomberg School of Public Health, Baltimore MD, available at: https://www. globaltobaccocontrol.org/e-cigarette_policyscan

Jarvis, M.J., Cohen, J.E., Delnevo, C.D. and Giovino, G.A. (2013), "Dispelling myths about gender differences in smoking cessation: population data from the USA, Canada and Britain", Tobacco Control, Vol. 22 No. 5, pp. 356-360.

Johns Hopkins (2018), "Countries that regulate heated tobacco products", available at: https:// www.globaltobaccocontrol.org/sites/default/files/Heated\%20tobacco\%20regulations_Jan\% 202019.pdf

Jones, L. (2019), "Vaping: how popular are e-cigarettes?", BBC News, September 15, available at: https://www.bbc.com/news/business-44295336 (accessed 10 December 2019).

Korea Times (2019), "Korea world's no. 2 heated tobacco market", July 19, available at: https://www. koreatimes.co.kr/www/tech/2019/07/693_271976.html (accessed 15 January 2020).

Lachenmeier, D.W., Anderson, P. and Rehm, J. (2018), "Heat-not-burn tobacco products: the devil in disguise or a considerable risk reduction?", The International Journal of Alcohol and Drug Research, Vol. 7 No. 2, pp. 8-11.

Livingstone-Banks, J., Norris, E., Hartmann-Boyce, J., West, R., Jarvis, M., Chubb, E. and Hajek, P. (2019), "Relapse prevention interventions for smoking cessation", Cochrane Database of Systematic Reviews, No. 2, pp. 1-146.

McNeill, A., Brose, L.S., Calder, R., Bauld. and Robson, D. (2018), "Evidence review of e-cigarettes and heated tobacco products, 2018. A report commissioned by public health England", Public Health England, London.

McNeill, A., Brose, L.S., Calder, R., Bauld. and Robson, D. (2020), "Vaping in England: an evidence update including mental health and pregnancy, March 2020: a report commissioned by public health England", Public Health England, London.

Mallock, N., Pieper, E., Hutzler, C., Henkler-Stephani, F. and Luch, A. (2019), "Heated tobacco products: a review of current knowledge and initial assessments", Frontiers in Public Health, Vol. 7 No. 287, pp. 1-8.

Mallock, N., Böss, L., Burk, R., Danziger, M., Welsch, T., Hahn, H., Trieu, H.-L., Hahn, J., Pieper, E., Henkler-Sephani, F., Hutzler, C. and Luch, A. (2018), "Levels of selected analytes in the emissions of 'heat not burn' tobacco products that are relevant to assess human health risks", Archives of Toxicology, Vol. 92 No. 6, pp. 2145-2149.

Meich, R.A., Johnston, L.D., O'Malley, P.M., Bachman, J.G., Schulenberg, J.E. and Patrick, M. (2019), Monitoring the Future National Survey Results on Drug Use, 1975-2018: Volume 1, Secondary School Students, Institute for Social Research, University of MI, Ann Arbor, MI.

Meier, B.M. and Shelley, D. (2006), "The fourth pillar of the framework convention on tobacco control: harm reduction and the international human right to health", Public Health Reports, Vol. 121 No. 5, pp. 494-500.

Meier, E., Lindgren, B.R., Anderson, A., Reisinger, S.A., Norton, K.J., Jensen, J., Strayer, L., Dick, L., Tang, M.-K., Chen, M., Carmella, S.G., Hecht, S.S., Murphy, S.E., Yang, J., Stepanov, I., O'Connor, R.J., Shields, P.G. and Hatsukami, D.K. (2019), "A randomized clinical trial of snus examining the effect of complete versus partial cigarette substitution on smoking-related behaviors, and biomarkers of exposure", Nicotine and Tobacco Research, Vol. 22 No. 4, pp. 473-481.

Mussulman, L.M., Scheuermann, T.S., Faseru, B., Nazir, N. and Richter, K.P. (2019), "Rapid relapse to smoking following hospital discharge", Preventive Medicine Reports, Vol. 15, pp. 1-4.

National Academies of Sciences, Engineering and Medicine (2018), Public Health Consequences of ECigarettes, National Academies Press, Washington, DC, available at: https://www.nap.edu/catalog/ 24952/public-health-consequences-of-e-cigarettes

Niaura, R. (2016), Re-Thinking Nicotine and Its Effects, Truth Initiative, Washington, DC, available at: http://truthinitiative.org/sites/default/files/ReThinking-Nicotine.pdf

Notley, C., Ward, E., Dawkins, L. and Holland, R. (2018), "The unique contribution of e-cigarettes for tobacco harm reduction in supporting smoking relapse prevention", Harm Reduction Journal, Vol. 15 No. 1, pp. 1-12. 
Nyman, A.L., Huang, J., Weaver, S.R. and Eriksen, M.P. (2019), "Perceived comparative harm of cigarettes and electronic nicotine delivery systems", JAMA Network Open, Vol. 2 No. 11, pp. 1-4.

O'Connor, R.J., Cummings, K.M., Rees, V.W., Connolly, G.N., Norton, K.J., Sweanor, D., Parascandola, M., Hatsukami, D.K. and Shields, P.G. (2009), "Surveillance methods for identifying, characterizing, and monitoring tobacco products: potential reduced exposure products as an example", Cancer Epidemiology Biomarkers \& Prevention, Vol. 18 No. 12, pp. 3334-3348.

Passport (2020), "Tobacco, database, Euromonitor international", available at: https://go.euromonitor. com/passport.html

Patel, D., Peiper, N. and Rodu, B. (2013), "Perceptions of the health risks related to cigarettes and nicotine among university faculty", Addiction Research \& Theory, Vol. 21 No. 2, pp. 154-159.

Ramstrom, L. and Wikmans, T. (2014), "Mortality attributable to tobacco among men in Sweden and other European countries: an analysis of data in a WHO report", Tobacco Induced Diseases, Vol. 12 No. 1, pp. 1-4.

Ramström, L., Borland, R. and Wikmans, T. (2016), "Patterns of smoking and snus use in Sweden: implications for public health", International Journal of Environmental Research and Public Health, Vol. 13 No. 11, pp. 1-14.

Rodu, B. and Plurphanswat, N. (2019), "Mortality among male smokers and smokeless tobacco users in the USA", Harm Reduction Journal, Vol. 16 No. 1, pp. 1-9.

Ryman, T.K., Boyer, B.B., Hopkins, S.E., Philip, J., Thompson, B., Beresford, S.A., Thummel, K.E. and Austin, M.A. (2018), "Association between iq'mik smokeless tobacco use and cardiometabolic risk profile among yup'ik Alaska native people”, Ethnicity \& Health, Vol. 23 No. 5, pp. 488-502.

Saffer, H., Dench, D.L., Grossman, M. and Dave, D.M. (2019), "E-cigarettes and adult smoking: evidence from Minnesota", Working Paper 26589, National Bureau of Economic Research, Cambridge, MA, available at: www.nber.org/papers/w26589

Schane, R.E., Ling, P.M. and Glantz, S.A. (2010), "Health effects of light and intermittent smoking: a review", Circulation, Vol. 121 No. 13, pp. 1518-1522.

Shahab, L., Dobbie, F., Hiscock, R., McNeill, A. and Bauld, L. (2016), "Prevalence and impact of longterm use of nicotine replacement therapy in UK stop-smoking services: findings from the ELONS study", Nicotine and Tobacco Research, Vol. 20 No. 1, pp. 81-88.

Shahab, L., Goniewicz, M.L., Blount, B.C., Brown, J., McNeill, A., Alwis, K.U., Feng, J., Wang, L. and West, R. (2017), "Nicotine, carcinogen, and toxin exposure in long-term e-cigarette and nicotine replacement therapy users: a cross-sectional study", Annals of Internal Medicine, Vol. 166 No. 6, pp. 390-400.

St. Helen, G.S., Jacob, P., III, Nardone, N. and Benowitz, N.L. (2018), "IQOS: examination of philip morris international's claim of reduced exposure", Tobacco Control, Vol. 27, pp. s30-s36.

Sutanto, E., Miller, C., Smith, D.M., O'Connor, R.J., Quah, A.C., Cummings, K.M., Xu, S., Fong, G.T., Hyland, A., Ouimet, J. and Yoshimi, I. (2019), "Prevalence, use behaviors, and preferences among users of heated tobacco products: findings from the 2018 ITC Japan survey", International Journal of Environmental Research and Public Health, Vol. 16 No. 23, pp. 1-18.

Tabuchi, T., Gallus, S., Shinozaki, T., Nakaya, T., Kunugita, N. and Colwell, B. (2018), "Heat-not-burn tobacco product use in Japan: its prevalence, predictors and perceived symptoms from exposure to secondhand heat-not-burn tobacco aerosol", Tobacco Control, Vol. 27 No. e1, pp. e25-e33.

US Department of Health and Human Services (US HHS) (2010), "How Tobacco Smoke Causes Disease: The Biology and Behavioral Basis for Smoking Attributable Disease: A Report of the Surgeon General", US Department of Health and Human Services, Washington, DC.

US Department of Health and Human Services (US HHS) (2020), Smoking Cessation. A Report of the Surgeon General, US Department of Health and Human Services, Atlanta, GA.

US Food and Drug Administration (2016), "FDA Drug Safety Communication: FDA revises description of mental health side effects of the stop-smoking medicines Chantix (varenicline) and Zyban (bupropion) to reflect clinical trial findings", available at: www.fda.gov/drugs/drug-safety-and-availability/fda-drugsafety-communication-fda-revises-description-mental-health-side-effects-stop-smoking

Vogel, E.A., Cho, J., McConnell, R.S., Barrington-Trimis, J.L. and Leventhal, A.M. (2020), "Prevalence of electronic cigarette dependence among youth and its association with future use", JAMA Network Open, Vol. 3 No. 2, pp. 1-13. 
Wackowski, O.A., Ray, A.E. and Stapleton, J.L. (2019), "Smokers' perceptions of risks and harm from snus relative to cigarettes: a latent profile analysis study", Addictive Behaviors, Vol. 91, pp. 171-174.

World Health Organisation (2003), "Framework convention on tobacco control (FCTC)", available at: http://apps.who.int/iris/bitstream/10665/42811/1/9241591013.pdf?ua1/41

World Health Organization (2019b), "Tobacco fact sheet", available at: https://www.who.int/news-room/ fact-sheets/detail/tobacco, (accessed 30 November 2017)

Zeller, M. and Hatsukami, D. (2009), "Strategic dialogue on tobacco harm reduction group. The strategic dialogue on tobacco harm reduction: a vision and blueprint for action in the US", Tobacco Control, Vol. 18 No. 4, pp. 324-332.

\section{Further reading}

Adriaens, K., Van Gucht, D. and Baeyens, F. (2018), "IQOS ${ }^{T M}$ vs e-cigarette vs tobacco cigarette: a direct comparison of short-term effects after overnight-abstinence", International Journal of Environmental Research and Public Health, Vol. 15 No. 12, pp. 1-20.

Carter, A., Miller, P.G. and Hall, W. (2012), "The ethics of harm reduction", in Pates, R. and Riley, D. (Eds), Harm Reduction in Substance Use and High-Risk Behavior: International Policy and Practice, WileyBlackwell, Ames, IA, pp. 111-123.

Gehricke, J.G., Loughlin, S.E., Whalen, C.K., Potkin, S.G., Fallon, J.H., Jamner, L.D., Belluzzi, J.D. and Leslie, F.M. (2007), "Smoking to self-medicate attentional and emotional dysfunctions", Nicotine \& Tobacco Research, Vol. 9, pp. S523-S536.

Owusu, D., Huang, J., Weaver, S.R., Pechacek, T.F., Ashley, D.L., Nayak, P. and Eriksen, M.P. (2019), "Patterns and trends of dual use of e-cigarettes and cigarettes among US adults, 2015-2018", Preventive Medicine Reports, Vol. 16, pp. 1-7.

Stephens, W.E. (2018), "Comparing the cancer potencies of emissions from vapourised nicotine products including e-cigarettes with those of tobacco smoke", Tobacco Control, Vol. 27 No. 1, pp. 10-17.

US Centers for Disease Control and Prevention (2019), "Outbreak of lung injury associated with ecigarette use or vaping", November 21, available at: https://www.cdc.gov/tobacco/basic_information/ecigarettes/severe-lung-disease.html (accessed 2 December 2019).

US Centers for Disease Control and Prevention (2020), "EVALI update”, February 25, available at: https:// www.cdc.gov/tobacco/basic_information/e-cigarettes/severe-lung-disease.html (accessed 20 March 2020).

US Department of Health and Human Services (US HHS) (2014), "The Health Consequences of Smoking: 50 Years of Progress: a Report of the Surgeon General”, US Department of Health and Human Services, Centers for Disease Control and Prevention, National Center for Chronic Disease Prevention and Health Promotion, Office on Smoking and Health, Atlanta, GA.

US Food and Drug Administration (2019a), "FDA grants first-ever modified risk orders to eight smokeless tobacco products", October 22, available at: https://www.fda.gov/news-events/press-announcements/ fda-grants-first-ever-modified-risk-orders-eight-smokeless-tobacco-products

US Food and Drug Administration (2019b), "FDA, DEA seize 44 websites advertising sale of illicit THC vaping cartridges to US consumers as part of operation vapor lock [news release]", December 20, available at: https://www.fda.gov/news-events/press-announcements/fda-dea-seize-44-websitesadvertising-sale-illicit-thc-vaping-cartridges-us-consumers-part-operation

US Food and Drug Administration (2020), "Modified risk tobacco products", February 12, available at: https://www.fda.gov/tobacco-products/advertising-and-promotion/modified-risk-tobacco-products\# summary

Weeks, C. (2020), "Vaping: what's known about the lung disease racking the US, risks to you and what health Canada is saying", The Globe and Mail.

World Health Organization (2018), WHO Global Report on Trends in Prevalence of Tobacco Smoking 2000-2025, WHO, Geneva.

World Health Organization (2019a), WHO Report on the Global Tobacco Epidemic 2019: Offer Help to Quit Tobacco Use, WHO, Geneva. 
World Health Organization (2019b), "Table 11.3.0, most recent survey of tobacco use, smoking or cigarette use among youth in WHO member states globally", available at: https://www.who.int/tobacco/ global_report/Table-11-3-Youth-surveys-tobacco-use-and-smoking.xls?ua=1

World Health Organization (2019c), "Tobacco fact sheet", July 26, available at: https://www.who.int/ news-room/fact-sheets/detail/tobacco (accessed 30 November 2019).

\section{Author affiliations}

Renée O'Leary is based at the Center of Excellence for the Acceleration of Harm Reduction, University of Catania, Catania, Italy.

Riccardo Polosa is based at the Center of Excellence for the acceleration of Harm Reduction, University of Catania, Catania, Italy; Dipartimento di Medicina Clinica e Sperimentale, University of Catania, Catania, Italy and Centro per la Prevenzione e Cura del Tabagismo (CPCT), Azienda Ospedaliero-Universitaria "Policlinico-V. Emanuele", Catania, Italy.

\section{Corresponding author}

Riccardo Polosa can be contacted at: polosa@unict.it

For instructions on how to order reprints of this article, please visit our website: www.emeraldgrouppublishing.com/licensing/reprints.htm

Or contact us for further details: permissions@emeraldinsight.com 